Table 1

Means and Standard Deviations of Trials to Criterion Scores in Transfer Leaming

\begin{tabular}{|c|c|c|c|c|c|}
\hline Shift & $\begin{array}{l}\text { Relevant Transfer } \\
\text { Learning Dimension }\end{array}$ & Condition & $\begin{array}{c}\text { Unconverted } \\
\text { Mean }\end{array}$ & Mean & S.D. \\
\hline Reversal & $\begin{array}{l}\text { Size } \\
\text { Brightness } \\
\text { Size } \\
\text { Brightness } \\
\text { Size } \\
\text { Brightness }\end{array}$ & $\begin{array}{l}0 \mathrm{~V} \\
0 \mathrm{~V} \\
1 \mathrm{~V} \\
1 \mathrm{~V} \\
2 \mathrm{~V} \\
2 \mathrm{~V}\end{array}$ & $\begin{array}{l}20.4 \\
23.7 \\
13.6 \\
23.6 \\
13.0 \\
18.4\end{array}$ & $\begin{array}{l}1.263 \\
1.269 \\
1.128 \\
1.245 \\
1.094 \\
1.225\end{array}$ & $\begin{array}{l}.222 \\
.295 \\
.066 \\
.332 \\
.135 \\
.201\end{array}$ \\
\hline Nonreversal & $\begin{array}{l}\text { Size } \\
\text { Brightness } \\
\text { Size } \\
\text { Brightness } \\
\text { Size } \\
\text { Brightness }\end{array}$ & $\begin{array}{l}0 \mathrm{~V} \\
0 \mathrm{~V} \\
1 \mathrm{~V} \\
1 \mathrm{~V} \\
2 \mathrm{~V} \\
2 \mathrm{~V}\end{array}$ & $\begin{array}{l}34.0 \\
30.3 \\
22.9 \\
33.1 \\
20.4 \\
34.3\end{array}$ & $\begin{array}{l}1.427 \\
1.405 \\
1.318 \\
1.508 \\
1.234 \\
1.445\end{array}$ & $\begin{array}{l}.332 \\
.272 \\
.203 \\
.115 \\
.251 \\
.300\end{array}$ \\
\hline
\end{tabular}

data also indicated that Ss learned more easily when size was the relevant dimension than when the relevant dimension was brightness $[F(1,72)=4.01, p<.05]$. Contrary to expectation, analysis of variance indicated no effect due to verbalization or to interaction.

One possible explanation of the above results concerns the influence of the instructions on subsequent discrimination performance. Since all Ss were given the entire universe of potentially relevant stimulus attributes-small, large, black, and white-in the initial instructions, it may be reasoned that this information tended to reduce the differential effects of the verbalization conditions. If mediation actually consists of covert verbalization, it may be hypothesized that once the mediating child is aware of the verbal labels for potentially relevant discriminations, the overt use of such labels will not necessarily provide additional support in the mediating process.

Failure to demonstrate verbal facilitation may have also been due to methodological problems caused by confounding the verbalization conditions with $R$ and $\bar{R}$. In one case (1VR), verbalization was within a dimension that was to become relevant during transfer learning. Previous research has illustrated the facilitative effects of relevant verbalization. In the other condition ( $1 \mathrm{~V} \overline{\mathrm{R}})$, verbalization was in a dimension that was to become irrelevant which, according to previous research, should retard shift learning. Thus, it can be argued that the two conditions would cancel each other out.

In the present design, one might expect an interaction in the IVR condition due to the training of irrelevant verbalization. This condition should have had the greatest number of trials to criterion among the three $\overline{\mathbf{R}}$ conditions. However, $1 \mathrm{~V} \overline{\mathbf{R}}$ did not differ from $O V \bar{R}$. The interaction probably would have occurred if it were not for the differential effects of size and brightness during the verbalization conditions. The data indicated that, during transfer learning, one- and two-dimension verbalization facilitated the acquisition of a size discrimination to a greater extent than a brightness discrimination. This distinction appeared to have cancelled out any possible interfering effects of verbalization in $1 V \bar{R}$.

As predicted, 2V required the fewest number of trials to criterion among the three verbalization conditions for both $R$ and $\bar{R}$. As in $1 \mathrm{~V}$, when brightness was the critical dimension, the ease of shift did not differ from $0 V$, therefore preventing the occurrence of any interaction effect demonstrating the facilitative effects of $2 \mathrm{~V}$.

During discrimination learning for $1 \mathrm{~V}, \mathrm{Ss}$ appeared to begin by selecting a size discrimination during the initial trials. When size was the criterial dimension, they appeared "unwilling" to surrender this label during $\bar{R}$ to brightness. But when brightness was the critical dimension during discrimination learning, Ss appeared to be more willing to use a size designation once they realized that their selections were no longer correct during shift learning.

Some evidence for this phenomenon is supported by Wolff's finding 1 that there is

\section{P. GOLD, Sir George Williams University, Montreal, P.Q., Canada}

Two groups each of male and female Ss were run 60 trials in an eyelid-conditioning experiment, either by an $E$ of the same or cross sex. It was predicted that the interaction between sex of $E$ and sex of $S$ would determine the conditioning level attained, rather than sex of S alone. The data an increase in preference for the size dimension at age 7 . However, Wolff did not find a corresponding increase in the emission of size labels.

If size appeared high on these Ss' verbal hierarchy, it may be reasoned that size was more difficult to extinguish during $\overline{\mathbf{R}}$, thus affecting the ease of shift from brightness to size as compared to the shift from size to brightness.

This same condition appeared to have influenced the effect of $2 \mathrm{~V}$. Although Ss verbalized both dimensions simultaneously, this condition did not serve to direct equal attention to both dimensions, and perhaps causing the similarity between $1 \mathrm{~V}$ and $2 \mathrm{~V}$.

In future studies of this type, data concerning (a) number of trials required in discrimination learning, (b) frequency of Ss' verbalizing size and brightness during IV, and (c) Ss' stimulus preferences should help explain any differential dimensional effects.

\section{REFERENCES}

MILGRAM, N. A., \& NOCE, J. S. Relevant and irrelevant verbalization in discrimination and reversal leaming by normal and retarded children. Journal of Educational Psychology, $1968,59,169-175$.

SMILEY, S. S., \& WEIR, M. W. The role of dimensional dominance in reversal and nonreversal shift behavior. Journal of Experimental Child Psychology, 1966, 4, 211-216.

WOLFF, J. L. Concept-shift and discrimination-reversal learning in humans. Psychological Bulletin, 1967, 68, 369-408.

WOLFF, J. L. The effect of subject-determined verbalization on discrimination learning in preschoolers. Paper delivered at the 1968 annual meeting of the American Educational Research Association, Chicago, Illinois. NOTE

1. Wolff, $\mathrm{I} . \mathrm{L}$. The role of stimulus preferences in discrimination-reversal leaming as a function of age. Unpublished manuscript, 1967.

\title{
Effect of the experimenter in human eyelid conditioning
}

revealed a significant $E$ effect, with the male $E$ consistently eliciting higher conditioning levels than the female $E$.

Rosenthal (1966) has presented evidence that seemingly irrelevant factors can produce powerful effects in psychological experiments. Such a factor is sex of the E (Rosenthal, 1967), which suggests that previous findings of different task 
performances by sex groups should be reconsidered.

One such finding is that of sex differences in attained conditioning levels. Spence \& Spence (1966) concluded that female Ss have a tendency to condition at a higher rate than male Ss in the standard conditioning situation. However, as far as available information indicates, male Es were consistently part of that standard situation, thereby possibly creating a differential sex effect on the Ss' performances.

The basic hypothesis of this study, therefore, is that $E$ characteristics have differential effects on Ss' performances in the conditioning situation. The present hypothesis attributes higher conditioning performance by female Ss not to some factor specific to females, such as their greater unfamiliarity with and consequent anxiety in laboratory situations, but to the interaction between sex of $\mathrm{E}$ and sex of S. It is predicted that when female Ss are tested by a male $E$, and when male $S s$ are tested by a female $E$, they will condition at a higher rate than when tested by an $E$ of the same sex. It is suggested that the intervening variable responsible for these results would be greater arousal or emotionality evoked in the situation with the cross-sex E handling the $S$ in the attachment of the recording devices to his or her face. The greater arousal level, indicative of a higher D or drive level, should consequently lead to better conditioning (Spence, 1960).

\section{METHOD}

Students from an introductory psychology course were used as Ss. Testing was carried out near the beginning of the first term so that $S s$ who were inexperienced with laboratory procedures could be used. Ss were randomly assigned to either a male or female $E$ who then tested male and female $\mathrm{Ss}$ in alternate order. Four groups of $25 \mathrm{Ss}$ each were thus tested.

The Es, two 4th-year psychology students, were unaware of the hypothesis of the study. The two Es were trained to follow identical procedures and to behave in a very formal manner, limiting their conversation strictly to the giving of the standard instructions and deferring any questions of the $S$ to the end of the experiment.

Each $S$ was individually tested, first completing the Manifest Anxiety Scale (Taylor, 1953), and then receiving the conditioning procedures. Since anxiety is significantly related to attained conditioning level (Spence \& Spence, 1966), the MAS was given to check the anxiety levels of each group. The conditioning trials were administered in a sound-treated, dimly illuminated ( $2 \mathrm{ft}-\mathrm{c}$ ) testing room. The $S$ sat at a table in a specially designed chair with an adjustable head holder. The E administered the conditioning trials from behind a screen with a one-way mirror.

The CS was an increase in brightness of a

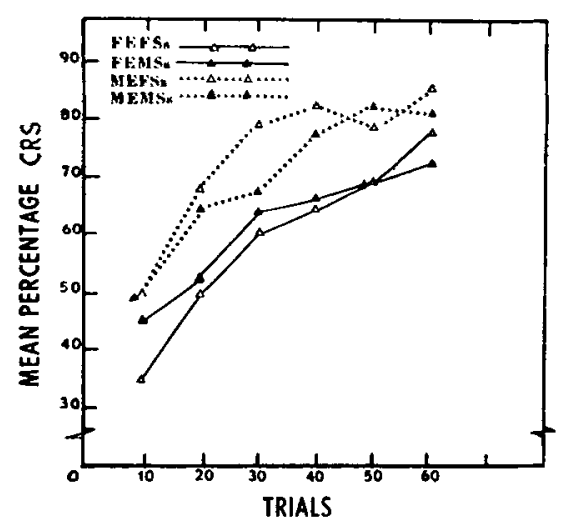

Fig. 1. Mean percentage CRS as a function of number of trials.

diffused red disc 24 in. in front of the $S$, lasting $500 \mathrm{msec}$. The UCS was a puff of air of 2.0 psi delivered to the cornea of the S's left eye by a Fisher 311 headpiece. The UCS lasted for $60 \mathrm{msec}$, with an interstimulus interval of $500 \mathrm{msec}$. The onset and durations of the CS and the UCS were controlled by Hunter interval timers. Eyeblinks were recorded by silver disc electrodes at tached above and below the left eye. The potential change in lid movement was amplified and recorded by a Grass 5D polygraph.

After the $\mathrm{S}$ was seated, he received a standard set of instructions. The instructions were modeled after those of McAllister \& McAllister (1958), in which the $S$ is given a brief description of conditioning. It is probable that some of the Ss had some knowledge of conditioning and, therefore, it was desirable that an attempt to standardize such knowledge be made.

After the equipment was adjusted and the instructions were read to the $S$, each $S$ received three presentations of the CS alone, followed by a single presentation of the UCS. The conditioning trials began about 1 min later. At random intervals of 2,3 , or $4 \mathrm{sec}$ before the $\mathrm{CS}$, a tone of $850 \mathrm{cps}$ sounded for a duration of $500 \mathrm{msec}$. At this signal, the $S$ was instructed to blink once and to fixate the disc. A total of 60 conditioning trials were given, with the intertrial interval avieraging $20 \mathrm{sec}$.

Voluntary responders and nonconditioners were eliminated, using the criteria established by Spence \& Ross (1959) and Spence \& Platt (1966). Eight Ss from the four groups were removed by the application of these criteria. CRs were defined as eyelid closures occurring between 300 and $500 \mathrm{msec}$.

\section{RESULTS AND DISCUSSION}

The four groups did not differ significantly from each other on the Manifest Anxiety Scale ( $F=1.65$, $\mathrm{df}=3 / 88, \mathrm{p}>.05)$. Figure 1 presents the conditioning performance of the four groups plotted as a function of blocks of 10 trials. An analysis of variance performed on all 60 trials produced a significant main effect for the $E$ variable $(F=11.847$, $\mathrm{df}=1 / 88, \mathrm{p}<.005$ ), but no significant effect for the sex of $S$ or for the interaction between sex of $S$ and sex of $E$.

Subjects of both sexes tested by the male E conditioned at a significantly higher level that Ss tested by the female E. Tests of least significant difference indicated that female Ss conditioned at a significantly higher level than male Ss when tested by the male E on four out of the six blocks, but male Ss compared to female Ss when tested by a female $E$ conditioned at a significantly higher level only once. The most striking effect on the data was that produced by the Es with the female E eliciting much less conditioning from both male and female Ss. Whether this effect was mediated by differing $E$ behavior or personality characteristics, or by the reactions of the Ss to the sex of the $E$, with the male $\mathrm{E}$ evoking more anxiety, is unknown. The training and restricted $S$ interaction of the two Es, however, favors the latter interpretation. Further work is necessary here. It is undeniable, however, that in conditions were attempts were made to minimize all differential effects of the $E$ except sex, this factor affected the data very strongly and much more significantly than the sex of the Ss. In view of the significantly higher conditioning levels achieved by female Ss compared to male Ss when tested by a male $E$, it appears that the $E$ effect is relevant to the previous studies on sex differences in conditioning.

\section{REFERENCES}

MCALLISTER, W. R., \& MCALLISTER, D. E. Effect of knowledge of conditioning upon eyelid conditioning. Joumal of Experimental Psychology, 1958, 55, 579-583.

ROSENTHAL, R. Experimenter effects in behavioral research. New York: Appleton-Century-Crofts, 1966.

ROSENTHAL, R. Covert communication in the psychological experiment. Psychological Bulletin, 1967, 67, 356-367.

SPENCE, K. W. Behavior theory and learning. Englewood Cliffs, N.J.: Prentice-Hall, 1960.

SPENCE, K. W., \& PLATT, J.R. UCS intensity and performance in eyelid conditioning. Psychological Bulletin, 1966, 65, 1-10.

SPENCE, K. W., \& ROSS, L. E. A methodological study of the form and latency of eyelid responses in conditioning. Joumal of Experimental Psychology, 1959, 58, 376-381.

SPENCE, K. W., \& SPENCE, J.T. Sex and anxiety differences in eyelid conditioning. Psychological Bulletin, 1966, 65, 137-142.

TAYLOR, J. A. A personality scale of manifest anxiety. Journal of Abnormal \& Social Psychology, 1953, 48, 285-290. NOTE

1. This research was supported by a research grant from the Committee on Aid to Scholarly Activity, Sir George Williams University. The author would like to express her gratitude to Linda Gold, Nat Kositsky, and Graham Burrow for their help in this project. 